in Human Behavior

Elsevier Editorial system(tm) for Computers

Manuscript Draft

Manuscript Number: CHB-D-15-00850R1

Title: Exploring flow experiences in cooperative digital gaming contexts

Article Type: Full Length Article

Section/Category: Full Length Article

Keywords: Digital games; flow; group flow; cooperative; groups

Corresponding Author: Dr. Linda K Kaye, PhD

Corresponding Author's Institution: Edge Hill University

First Author: Linda K Kaye, PhD

Order of Authors: Linda K Kaye, PhD

Abstract: Given the social nature of digital gaming, an investigation into social processes underpinning the experiences within social contexts of play is greatly warranted. The current research explored the underpinnings of "group flow" within cooperative-based gaming. In particular, this was intended to provide insight into the social processes which facilitate flow experiences in these contexts. This was achieved through a questionnaire in which gamers $(\mathrm{N}=76)$ provided retrospective open-ended accounts of flow during cooperative gaming. Additionally, quantitative data was obtained on flow and post-gameplay mood within this experience, as well as in solo gaming for comparative analysis. Thematic analysis of the qualitative responses revealed a number of factors which determined the experience of flow. These were; effective communication and team-work and task relevant knowledge of group members. Additionally, although flow was found to be lower in cooperative versus solo gaming, no differences in post-gameplay mood were observed. These findings aid conceptual development of facilitators of group flow in cooperative gaming, with insights into how this may extend to other cooperative activities. Additionally, they also provide new practical insight for representatives in the gaming industry on how gaming may be developed with the aim of promoting positive shared group experiences. 
Department of Psychology

Edge Hill University

St Helens Road

Ormskirk

Lancashire

L39 4QP

Linda.kaye@edgehill.ac.uk

Dear Professor Patricia Ordonez de Pablos,

\section{Re: CHB-D-15-00850}

Thank you for your review of the above manuscript and consideration to accept a revised version. In light of the reviewer comments, I have made a number of revisions to the manuscript which I feel address the concerns raised previously. I itemise each of these specifically within my response document and provide detail on how these are addressed.

Please see attached my revised manuscript, to be re-considered for publication in Computers in Human Behavior. The research reported in this manuscript was undertaken at Edge Hill University. I have read the Author Instructions for your journal. I hereby affirm that the content of this manuscript is original. Furthermore it has been neither published elsewhere fully or partially or any language nor submitted for publication (fully or partially) elsewhere simultaneously. The treatment of participants comply fully with the ethical guidelines published by the BPS.

Yours sincerely,

L. K. Kaye 

Table 1: Response to reviewer comments (CHB-D-15-00850)

\begin{tabular}{|c|c|}
\hline Comment & Response \\
\hline \multicolumn{2}{|c|}{ Reviewer 1} \\
\hline $\begin{array}{l}\text { The manuscript should have an } \\
\text { introduction and theoretical review section. } \\
\text { The introduction and conclusion section } \\
\text { need to clearly address how the } \\
\text { manuscript contributes to the advance of } \\
\text { the field. }\end{array}$ & $\begin{array}{l}\text { Thank you for your suggestions. More } \\
\text { detail has been added to the } \\
\text { Discussion section to provide further } \\
\text { insight into the contributions of the } \\
\text { current findings in the field of flow in } \\
\text { gaming. Little evidence is available on } \\
\text { the concept of group flow, making a } \\
\text { theoretical review at the start of the } \\
\text { manuscript quite tricky. However, the } \\
\text { key findings are presented with } \\
\text { indication of the rationale of the current } \\
\text { research in light of previous limitations } \\
\text { in this area. }\end{array}$ \\
\hline $\begin{array}{l}\text { Methodology section needs further } \\
\text { elaboration. For example, the description } \\
\text { of the sample and procedure is too short. }\end{array}$ & $\begin{array}{l}\text { Within this section, further details on } \\
\text { the gamer types has been added as } \\
\text { well as details on the analytic strategy. } \\
\text { Additionally, as a quantitative element } \\
\text { has been added to the results, this is } \\
\text { reflected in further details on materials } \\
\text { being added in the Method }\end{array}$ \\
\hline $\begin{array}{l}\text { Section "Results/Discussion" should have } \\
\text { a proper title. }\end{array}$ & $\begin{array}{l}\text { For qualitative research, it is not } \\
\text { uncommon for Results and Discussion } \\
\text { sections to be combined as such. } \\
\text { However, these sections have now } \\
\text { been separated given the quantitative } \\
\text { data which has now been added to this } \\
\text { manuscript. }\end{array}$ \\
\hline $\begin{array}{l}\text { Conclusion section is too brief and } \\
\text { required more elaboration as well as } \\
\text { discussion of the limitations, if any, of the } \\
\text { study. }\end{array}$ & $\begin{array}{l}\text { The Discussion section has been } \\
\text { expanded, including the conclusion } \\
\text { (now merged into "Discussion" rather } \\
\text { than a separate sub-heading). For } \\
\text { example, details on the study } \\
\text { limitations and conceptual contributions } \\
\text { have been added. }\end{array}$ \\
\hline \multicolumn{2}{|c|}{ Reviewer 2} \\
\hline $\begin{array}{l}\text { The definition of "flow" should be included } \\
\text { before starting to use it as this is an } \\
\text { interdisciplinary journal and some readers } \\
\text { might not be familiar with the term. }\end{array}$ & $\begin{array}{l}\text { Thank you for your suggestions. The } \\
\text { definition has now been moved earlier } \\
\text { so it follows the first mention of "flow" to } \\
\text { aid the reading, particularly for those } \\
\text { from non-psychology disciplines. }\end{array}$ \\
\hline $\begin{array}{l}\text { Please provide a definition for the gamer } \\
\text { categories you use (hardcore/experiences, } \\
\text { serious, etc) }\end{array}$ & $\begin{array}{l}\text { Details have been added regarding } \\
\text { definitions of gamer types in line with } \\
\text { Juul (2010) for example. }\end{array}$ \\
\hline
\end{tabular}


Please include descriptive statistics (mean, sd, min, max) for how much subjects play digital games as well as their ages

The beginning of the results section (where you describe the data analysis) should be moved to the methods section

Also, you should provide enough detail on the data analysis (identification of themes and codes) for others to be able to replicate your methods

It would be nice to include a more elaborate analysis of your data using statistical methods (e.g. compare online versus offline games, compare different types of games such as adventure/shooting/etc, compare genders, age groups, more versus less experienced gamers) I would also applaud a follow-up study focusing on the themes (communication, team-work, task-relevant knowledge of others) that you identified to be important and collect quantifiable data (e.g. using Likert scales) in order to statistically analyse their relationship to flow experience, and related positive emotions, etc.

If you decide to run this follow-up you might also consider collecting more data on the gaming context (e.g. number of players involved, if the players know each other or the game is anonymous, etc - you might already have some of these data in which case you could report it) as well as on the subjects (e.g. standard psychology questionnaires).
The data for age and hours per week was obtained by asking participants to select a box (e.g., 18-25 years, 26-35 years etc) therefore the descriptive analysis requested cannot be performed given the categorical nature of the obtained data. However, the frequency analysis provided should give an overview of these insights.

The data analysis description has been moved to the Method section.

Further detail has been added on the analytic strategy, particularly in relation to the development of themes in the data.

This research did actually obtain some quantitative data on experiences of flow and mood in these cooperative experiences, relative to a solo gaming experience. Here participants used established scales for flow and mood to rate the extent to which they experienced these in respect of the experience they were reporting on. Therefore, this data has now been included which provides insight into how flow and post-gameplay mood (positive and negative) differ between cooperative versus solo gaming experiences. Further, sub-group analysis between online and offline contexts is also provided.

Additionally, the group flow items of the FSS which map on to the qualitative themes of communication, taskrelevant knowledge and team-work have been correlated with the mood outcomes to demonstrate their relevance to the emotional experiences of gaming. 

Highlights (for review)

Highlights

- An exploration of "real-world" accounts of social gaming

- An exploration into the social processes underpinning flow

- Evidence to indicate group flow in digital gaming 
FLOW IN COOPERATIVE DIGITAL GAMING

Exploring flow experiences in cooperative digital gaming contexts

Linda K. Kaye

Edge Hill University, UK

Correspondence should be addressed to Linda K Kaye, Department of Psychology, Edge Hill University, St Helens Road, Ormskirk, L39 4QP

+441695584413

Linda.kaye@edgehill.ac.uk 


\title{
Exploring flow experiences in cooperative digital gaming contexts
}

\begin{abstract}
Given the social nature of digital gaming, an investigation into social processes underpinning the experiences within social contexts of play is greatly warranted. The current research explored the underpinnings of "group flow" within cooperative-based gaming. In particular, this was intended to provide insight into the social processes which facilitate flow experiences in these contexts. This was achieved through a questionnaire in which gamers $(N$ =76) provided retrospective open-ended accounts of flow during cooperative gaming. Additionally, quantitative data was obtained on flow and post-gameplay mood within this experience, as well as in solo gaming for comparative analysis. Thematic analysis of the qualitative responses revealed a number of factors which determined the experience of flow. These were; effective communication and team-work and task relevant knowledge of group members. Additionally, although flow was found to be lower in cooperative versus solo gaming, no differences in post-gameplay mood were observed. These findings aid conceptual development of facilitators of group flow in cooperative gaming, with insights into how this may extend to other cooperative activities. Additionally, they also provide new practical insight for representatives in the gaming industry on how gaming may be developed with the aim of promoting positive shared group experiences.
\end{abstract}

Keywords: Digital games; flow; group flow; cooperative; groups 


\section{Introduction}

It is widely accepted that playing digital games with others can enhance the experiences of the activity, particularly for positive mood, arousal and engagement (Gajadhar, Kort, \& Ijsselsteij, 2008, 2009; Kaye \& Bryce, 2014; Mandryk, Inkpen, \& Calvert, 2006; Ravaja, Saari, Turpeinen, Laarni, Salminen, \& Kivikangas, 2006). For example, previous research has typically identified differences in psychological and physiological effects between conditions of participants undertaking gaming tasks with other humans versus computer-controlled opponents (Eastin, 2006, 2007; Lim \& Lee, 2009; Lim \& Reeves, 2010). These findings suggest that social contexts of gameplay are an important determinant of the experiences and outcomes of the activity, highlighting the need for further research to address specific questions which may be raised from such research.

One such issue relates to the extent to which these previously observed differential outcomes are relevant to "real world" gaming experiences. That is, the typical laboratory setting may not be considered to be the most representative context for exploring everyday social gaming, which can be largely dynamic and varied in nature (Kaye \& Bryce, 2012). Thus, it could be argued that findings have little external validity to understanding the psychological and social underpinnings of real-world gaming experiences. Additionally, it remains unclear about the particular social processes which may underpin enhanced experiences in cooperative-based gaming, and particularly how these may function in facilitating the experience of flow (Csikszentmihalyi, 1975), for example. Specifically considering "flow", this is defined as characterising an experience in which an individual feels "in the zone" during an intrinsically motivated and enjoyable activity (Csikszentmihalyi, 1975). The original flow framework outlines a number of key conditions and characteristics which underpin the flow experience 
(Csikszentmihalyi, 1975). These are; a balance of an individual's skill to meet a high challenge of a task, clear goals of a task, unambiguous feedback, focused attention, loss of self-consciousness, distorted sense of time, sense of control, and an overall autotelic experience. Whilst this original framework considered flow as an individual experience, more recent commentary has identified its utility to explain shared experiences, otherwise known as any of the following; "shared flow", "group flow" or "networked flow" (Gaggioli, Milani, Mazzoni, \& Riva, 2011; Gaggioli, Riva, Milani, \& Mazzoni, 2012; Nakamura \& Csikszentmihalyi, 2002; Sawyer, 2008; Sato, 1988; Walker, 2010). Some features found to be relevant in shared experiences of flow are; companionship, sense of belonging, and interactivity among group members (Rufi, Wlodarczyk, Páez \& Javaloy, in press; Sato, 1988). Similarly, aspects of interactivity on group identity and processes have been found to be relevant for social gaming, supporting the application of flow in digital gaming contexts (Argenton, Triberti, Serino, Muzio, \& Riva, 2014; Chiang, Lin, Cheng, \& Liu, 2011). Along similar lines, research findings in the similar fields of immersion and social presence are helpful to consider here (see Brown \& Cairns, 2004; Gajadhar, de Kort \& IJsselsteijn, 2008, 2009a, 2009b). Namely, research on social presence (i.e. a player's awareness of another through a mediated environment) has found that context, co-location and relatedness between players (i.e. online others, "real-world friends") has little impact on the behavioural involvement experienced during gameplay (de Kort, IJsselsteijn, Poels, 2007). Similarly, flow experiences have been found to be largely equivalent when comparing solo and social gameplay contexts, as well as those between online versus offline gaming (Kaye \& Bryce, 2014).

However, although previous research has considered the extent to which the experience of "flow" may be experienced within social-based gaming contexts (Kaye \& Bryce, 2012) and 
whether this differs from solo-based gaming (Kaye \& Bryce, 2014), the variety of group processes which underpin so-called "group flow" are not yet fully established. In particular, research exploring these issues in reference to specific gameplay contexts would be a beneficial line of enquiry. For example, greater focus is needed on exploring the social underpinnings of specific forms of gameplay (e.g., cooperative). Specifically when considering cooperative-based gameplay (i.e. two or more players undertaking a task which requires complementary participation to accomplish a shared goal), previous evidence shows flow to occur as the result of parallel and organised tasks, characterised by a shared sense of social belonging and collective competency (Kaye \& Bryce, 2012). Additionally, awareness of other players' skills is particularly relevant in the group flow framework, based on the findings of research on competitive forms of gameplay (Kaye \& Bryce, 2012). However, there is little available empirical evidence which identifies any further insights into this issue. Namely, what social factors and processes are most relevant in the context of cooperativebased gaming for promoting a shared experience of flow? Previous research enquiries have also failed to draw clear distinctions in experiences of group flow as a product of context of play (i.e., online versus offline). This formed the basis for the current study, in exploring gamers' selected self-reports of cooperative-based gameplay, to explore the facilitators of "group flow" within these contexts. This was achieved through obtaining gamers' qualitative accounts of their experiences in respect of cooperative-based gaming. Additionally, quantitative reports of players' experiences of flow and post-gameplay mood were also obtained in respect of these cooperative experiences as well as in solo gameplay, as a means of providing a comparative analysis of these issues between contexts. This formed the basis for the formation of a number of research questions:

RQ1: What are the facilitators of "group flow" within cooperative-based gaming? 
RQ2: To what extent are flow and post-gameplay mood different between cooperative and solo gaming contexts?

\section{Method}

\subsection{Design/Procedure}

A web-link to an online questionnaire was advertised to digital gamers on numerous online gaming sites and discussion boards. Participants were asked to consider a recent cooperative gaming experience, and provide an open-ended account of the experiences and feelings they had derived from this (e.g., "Please provide an account of the experiences and feelings you got from this gameplay session"). To obtain further details on these experiences, participants were asked to indicate what type of game and gameplay context (online or offline) these experiences related to. Additionally, participants were also asked to provide quantitative selfreport ratings for the experience of flow, positive and negative mood following gameplay in respect of this cooperative experience, as well as a recent solo gaming experience for comparative analysis.

To explore key indicators of group flow in cooperative gameplay contexts, analysis of the open-ended responses were analysed using thematic analysis. This was undertaken in line with Braun and Clark's (2006) suggested strategy. This included the written responses being read through numerous times to aid familiarisation of the data. Following this, initial themes were identified which were then further scrutinised by identifying codes within the data. For a "theme" to be identified as such, it had to characterise a pattern in the responses in which at least a description of a phenomena is identified (Boyatzis, 1998). These themes were reviewed in line with the data, in which a "codebook" was developed as a means of organising the responses for fuller interpretation (Crabtree \& Miller, 1999). Themes of 
“communication", “team-work", and "task-relevant knowledge of others" were identified through this process in which these were given a definition and description in line with previous procedures in thematic analysis (e.g., Crabtree \& Miller, 1999; Fereday \& MuirCochrane, 2006). Finally, relevant extracts were chosen to reflect the themes as illustrations within the written report of the research.

\subsection{Participants}

Participants were digital gamers $(N=76)$, who mainly identified themselves as being hardcore/experienced gamers $(42.1 \%)$. Others were "serious" gamers $(18.4 \%)$, "casual" gamers $(23.7 \%)$ and "social" gamers (10.5\%). Gamer descriptions were used in line with previous literature pertaining to these categories (e.g., Juul, 2010). Specifically, "hardcore/experienced" gamers are those who identify themselves as being more dedicated or invested as a gamer compared to those who are more "casual" by nature. "Serious" gamers, however differ in their investment from a professional-standpoint (e.g., might play or make games for a living). Finally, "social" gamers identify as such based on their primary motivation of play being attributed to socialising with others. Although these categories are not necessarily mutually exclusive, these were obtained through participants' own appraisals of the category which they felt most relevant to them. The majority of participants reported that they played digital games on average, for at least five hours per week $(80.3 \%)$, and $22.4 \%$ of these reported that this exceeded 30 hours per week. The majority of participants were male (71.1\%), aged between 18 and 25 years $(63.2 \%)$.

\subsection{Materials}

\subsubsection{Flow}


The Flow State Scale-Short Form (Jackson \& Eklund, 2002; Jackson, \& Marsh, 1996) was used to measure the experience of flow in the cooperative-based gaming contexts, as well as a solo one. Participants were asked to rate the extent to which they agreed with a series of eight statements about their experiences of flow on a 5 -point scale $(1=$ strongly disagree, $5=$ strongly agree). Items included "I felt I was competent enough to meet the high demands of the task"; and "I had a good idea while I was performing about how well I was doing" For the cooperative gaming context, a modified version of the FSS-Short Form was used in which the items were framed in relation to group indicators of flow (e.g., "We had a good idea while we were performing about how well we were doing"). Additionally, five further items were added to measure task-relevant knowledge of others ("Group members had task-relevant knowledge and skills about each other"), group cooperation ("The task required interdependence, coordination and cooperation"), complementary participation ("The task required complementary participation"), group feedback ("Group members focused on each other as well as the task to receive feedback") and group communication ("There was emotional communication during gameplay"). These additional items were added to assess a number of constructs previously found to be relevant for "group flow" in cooperative gaming contexts (Kaye \& Bryce, 2012). A mean flow score was obtained for each gaming experience and used in the subsequent analyses. Previous research has found the short form version of this scale to have acceptable construct validity (Jackson, Martin, \& Eklund, 2008). The current study calculated alpha coefficients as being adequately reliable both in solo $(\alpha=.72)$ and cooperative gaming contexts $(\alpha=.87)$.

\subsection{2. $M o o d$}

The Positive and Negative Affect Schedule (PANAS) (Watson, Clark, \& Tellegen, 1988) was used as a measure of positive and negative mood following gameplay. Participants were 
asked to consider the extent to which each of the 20 items on emotions described them in reference to their mood following both their solo and cooperative gaming experience. This was completed on a 5-point scale ( $1=$ very slightly/not at all, $5=$ extremely). Positive items included "interested" and "determined", and negative items included "hostile" and "jittery". The mean scores for the two sub-scales of Positive Affect and Negative Affect were calculated and used in subsequent analyses. Previous research has identified the Positive and Negative Affect Schedule scale to be reasonably high both internal consistency, and in testretest reliability (Watson et al., 1988). The current study found similar reliability, with alpha coefficients of .91 for Positive Affect and .78 Negative Affect in solo gaming contexts. The alpha coefficients were .93 for Positive Affect and .87 for Negative Affect in cooperativebased gaming contexts.

\section{Results}

\subsection{Open-ended responses (Accounts of cooperative experiences)}

\subsubsection{Communication}

Effective verbal communication appeared to be an important facilitator for positive experiences. That is, a number of participants identified this to be key for effective groupbased play, and could be a detriment to group dynamics if this was not fulfilled:

\section{Extract 1:}

"It was good fun, but there was small amount of lack of communication that caused friction within the group - however this didn't stop the overall experience being enjoyable." (Adventure game, offline)

\section{Extract 2:}


"This session required some discussion on approach with my fellow players. This sometimes produced a little frustration if agreement could not be made but also happiness in our social interactions/discussions. During play there was constant mild challenge on our skills and further planning was required - this made the session more stimulating in both a social and gameplay sense." (Shooting game, online)

The impact of the nature of communication therefore, appears to be relevant for experiences which relate directly to gameplay processes as well as the social dynamics beyond gameplay. Interestingly, as extracts 1 and 2 indicate, the importance of effective communication is relevant both within online and offline forms of cooperative play. Indeed, the social interactions with friends within cooperative play was not only enjoyable, but was also found to be key for high performance:

\section{Extract 3:}

"Played Halo Reach online with a team consisting of friends. I like the social aspect of playing together and the communication needed to perform at a high level." (Shooting game, online)

Here, the communication could be used to the highest advantage when being used for strategic planning in cooperative-based contexts:

\section{Extract 4:}

“The game allows voice and/or text communication, giving players a means to strategise before, during and after each match, adding to the social aspect of the game." (Shooting game, online) 
Clearly, there are practical implications of the way in which cooperative-based games can be developed to facilitate effective forms of communication, particularly through online play in which communication is dependent on either voice or text-based methods. Additionally, there may be avenue here to consider the extent to which other forms of communication may be relevant, particularly within offline forms of gaming. For example, non-verbal communication and its likely role in promoting emotional contagion may be interesting to pursue here to consider whether this plays a role in facilitating a shared sense of purpose and experience to aid the processes of gameplay. These notions are reflective of those proposed by Biocca et al (2001) in the theory of "networked minds" and associated evidence which posits the role of gestures, interpersonal distance and gaze direction, for example, as determinants of interpersonal engagement (Argyle \& Dean, 1965; Goffman, 1956; Hall, 1959). However, in respect of flow, this is yet to be established, although the current findings provide some insight of this, particularly on the importance of verbal forms of communication in online cooperative contexts. Indeed it would be interesting to empirically explore these effects between previously acquainted and non-acquainted individuals (i.e. existing friendships versus strangers) to assess the non-verbal indicators associated with these groupings and how this functions for experiences of flow in offline cooperative gameplay. This may help provide evidence of the function of social groups (and their constitution) on interpersonal indicators associated with positive gameplay engagement.

\subsubsection{Team-work}

Along similar lines, effective team-work (often fostered through communication) underpinned positive gameplay experiences, particularly in the elements of cooperation required to achieve shared goals: 


\section{Extract 5:}

"There's the joy of co-operation to achieve a goal, the excitement of the action elements and the satisfaction of solving the puzzles together (we have to communicate more in this sense and try to explain what we're thinking we should do next). This sometimes leads to frustration but mostly due to my inability to sometimes communicate the brief flashes of a solution that pass through my mind." (Adventure game, offline)

Additionally, other accounts highlighted the role of individual players' skill in reference to the effectiveness of team-work:

\section{Extract 6:}

"Played several games of League of Legends with friends from across Europe against many different teams, posing separate levels of skill and challenge. Each individual game relied heavily on teamwork, positioning and personal skill. As each game was unique they all provided different experiences with some resulting in victory causing personal enthusiasm while others resulted in defeat spawning slight annoyance but also pushed me onto the next victory" (Action game, online)

As Extract 6 above highlights, the performance factors of gameplay (e.g, victory versus defeat) hold key implications to the emotional outcomes of gameplay, indicating how team performance here is key to personal experiences for individual players. This suggests the importance of developing effective team-building mechanisms as well as building collective 
competency within gaming groups, as previously noted, particularly within cooperative-based gaming (Kaye \& Bryce, 2012). This is highlighted further in Extract 7 below:

\begin{abstract}
Extract 7:
"...The game is heavily reliant on teamwork and communication for the group to succeed. Given that the game pairs the player up with four other random strangers to make up the group there is a certain level of discord in the group. It's mostly a hit or miss experience depending on how your group co-operates. If you get a bad group the experience is pretty miserable and you're almost guaranteed to fail. If you get a good group then you're almost guaranteed a win as good teamwork is pretty much all that's required at non-professional levels of play....I do feel a slight amount of frustration when teammates do things that are illogical or the team just refuses to cooperate but other than that the experience is enjoyable and rewarding. After each session I usually reflect on how I performed and how I can improve to help the team and myself. I will feel slightly guilty if I my performance isn't up to par with what I believe I am capable of." (Battle game, online)
\end{abstract}

Here, there is clear evidence of the important of mutual competency among group members and its impact on psychological and emotional experiences of the activity. Specifically, effective team-working and cooperation appears to facilitate enjoyable experiences, in contrast to those which are more disjointed by nature, resulting in frustrating experiences. Whilst these effects have been previously noted in socially-based gaming contexts (Kaye \& Bryce, 2012), the role of team dynamics present new insights into the underpinnings of these differential experiences. Therefore, findings of this nature may provide more specific practical insight for games representatives for developing effective strategies for aiding 
effective team-work processes in games. Namely, tasks which may facilitate team-building between groups of players, particularly those who may be previously unacquainted would be greatly beneficial in this regard. Similarly, this suggestion may also provide practical benefit for the theme of "task-relevant knowledge of others", discussed subsequently in Section 3.1.3.

\subsubsection{Task-relevant knowledge of others}

Further to the previously identified themes of "communication" and "team-work", it was also evident that "task-relevant knowledge of others" played an important role in cooperativebased gameplay. In particular, this related to acknowledging the less competent members of the group to ensure that effective team performance is maintained:

\section{Extract 8:}

"There is a strong sense of helpfulness. If a member of the party dies in combat, someone will always run back to revive them. Each person plays their roles and if there is a low level in the group, the high levels will typically look after them and make sure they don't die anywhere. So in this regard there is a mutual understanding between everyone playing and we are still able to cooperate without actually saying anything" (Game not disclosed, online)

Similarly, this mechanism allowed cooperation on skill-building within problem-solving aspects of gameplay, from one more competent player to another. In this way, the taskrelevant knowledge of others' skills was particularly important for facilitating this process, and thus aided the overall positive experience for all players: 


\section{Extract 9:}

“The game I played was Goof Troop for the SNES, which I played alongside one of my best friends. As I am a regularly gamer and he is not, I took the role of mentor and led him through the game. As such, I gained a feeling of pride as I saw him grasp the mechanics of the game and become more competent at it. This also led to a small increase in pressure, and a trace of anxiety as I needed to live up to my reputation as a gamer and an intelligent person. I was excited about playing this game with my friend as previously I have only been able to convince him to play skill based AAA games, such as FIFA and Call of Duty.....Finally, the game was a bonding experience. The act of solving puzzles together gave us a greater knowledge of how each other thinks and how we differ in approach to problems. We also felt proud both of ourselves and of each other when we completed each puzzle.” (Puzzle game, offline)

Here it is evident that awareness of the competencies of others within group-based cooperative play is vitally important for facilitating gameplay processes, in turn, positive gameplay experiences. Indicators of player skill or experience is therefore a key practical implication of the current findings, in ensuring either mutual, collective competency is maintained, or conversely, that group members are able to identify any potential members who may benefit from more scaffolded learning strategies in gameplay from more competent members.

\subsection{Quantitative responses (Solo versus cooperative experiences)}

To follow up these qualitative findings, and assess the extent to which cooperative-based contexts fostered flow and (positive) emotional experiences compared to solo ones, a 
comparison of self-reported flow and post-gameplay mood was undertaken between contexts. Specifically, descriptive analyses were undertaken to document mean flow and mood scores between the two gaming contexts (see Table 1 below).

\section{[Table 1 about here]}

Analyses were undertaken to establish the extent to which flow and mood was experienced differently between solo and socially-cooperative gameplay contexts. Specifically for flow, solo experiences appeared to foster flow to a significantly greater extent than cooperativebased ones $[t(49)=2.58, p<.05]$. However, no differences were observed for experiences of post-gameplay positive $[t(44)=.22, p=.829]$ or negative mood between the two contexts $[t$ $(55)=.94, p=.349]$. Therefore, although flow was experienced to a greater extent when playing solo, the associated emotional experiences of gameplay were equivalent. To examine further, sub-group analysis was conducted on flow and mood scores between those cooperative experiences in online compared to offline contexts. This revealed no significant differences for flow $[t(51)=.11, p=.910]$, positive $\operatorname{mood}[t(46)=.02, p=.981]$ or negative mood following gameplay $[t(58)=.21, p=.835]$.

Finally, items of the FSS used specifically to measure "group flow", which aligned with the qualitative themes were correlated with positive and negative mood to assess the extent to which these were associated with emotional outcomes of cooperative play ${ }^{1}$. All items were

\footnotetext{
${ }^{1}$ The FSS items used for each of the themes were as follows: communication: "There was emotional communication during gameplay"; task-relevant knowledge and skills: "Group members had task-relevant knowledge and skills about each other"; and team-work: "The
} 
significantly positively correlated with positive mood but none with negative mood, highlighting the positive role of these social processes within the emotional experiences of the activity. See Table 2 below for correlation coefficients.

\section{[Table 2 about here]}

\section{Discussion}

The primary aim of the current study was to explore the underpinnings of group flow within cooperative-based gaming, and secondly, provide a comparative account of experiences of flow and mood between solo and cooperative gaming contexts. In respect of the first objective, the findings further the limited research along this line of enquiry, and identify the facilitating features of cooperative play which may promote experiences of "group flow". The findings revealed a number of factors which appear to determine the extent to which flow may be experienced. These include; effective group communication, knowledge of others' skills and effective team-working. These findings provide new theoretical insight into the concept of group flow in reference to specific gaming contexts. It is hoped that research of this nature may aid the development of a more full conceptual understanding of the operationalisation of flow in cooperative-based gaming contexts as well as proving beneficial on a practical level for representatives in the gaming industry. Additionally, the mechanisms reported here may provide further practical insight into the way flow through digital gaming may be harnessed for promoting wider cooperative interpersonal activities. For example,

task required interdependence, coordination and cooperation" and "The task required complementary participation" 
technologies such as digital games which may be used as tools through which to promote engagement have key educational implications, as noted previously (Gee, 2003; Prensky, 2001). However, the current findings offer new insight into the social mechanisms which may underpin flow specifically for cooperative-based tasks, which are becoming increasingly more common within educational provision. Digital games in this way may offer exciting opportunities for promoting positive educational outcomes, when the social processes of these experiences are managed effectively. Thus, the current findings provide initial conceptual insight into cooperative-based flow which has clear wide implications beyond digital gaming.

In light of the second objective of this research, the findings revealed flow to be experienced differently between solo and cooperative gaming, but not between online versus offline contexts. This furthers the current understandings of these experiences within digital gaming. Specifically, although previous research has identified few differences in flow and mood between online and offline gaming (Kaye \& Bryce, 2014), no research to date has examined these specifically for players' real-world cooperative experiences. Additionally, taking this finding in light of the qualitative accounts suggests that the factors such as effective communication in promoting group flow functions equivalently in this regard between online and offline contexts. Therefore, regardless of the social context of play, the social affordances through communication, as well as other factors, remain instrumental for positive psychological gaming experiences. This is further supported by the finding that the conditions of "group flow" derived from the FSS were positively related to positive mood following gameplay. Clearly, the nature of these social dynamics within play are influential to the psychological and emotional outcomes of the activity. 
Although the current findings provide insight into "real world" gaming experiences, this concurrently raises some methodological issues. Namely, relying on participants' retrospective accounts of gameplay may be considered problematic in respect of the fallibility of memory and the limitations of autobiographical and episodic memory (e.g. Loftus \& Hoffman, 1989). Therefore, the accuracy of these accounts could come into question. Additionally, one could argue that a positive bias is characteristic of this type of methodological approach, in that participants may have been likely to remember, and therefore report on positive experiences rather than those more negative in nature. Therefore, the current findings should be considered in light of these methodological limitations.

Regardless of these methodological shortcomings, the current findings provide new conceptual insight into the underpinnings of group flow and its function in promoting positive gaming experiences (specifically, for positive mood). This presents exciting new directions for theorising on flow in digital gaming, where the focus to date has predominantly been related to solo gaming. However, with the increasingly social nature of gaming, this calls for further empirical investigation into the dynamic and varied experiences which can be afforded to the activity.

\section{Author Disclosure Statement}

No competing financial interests exist

\section{References}

Argenton, L., Triberti, S., Serino, S., Muzio, M., \& Riva, G. (2014). Serious games as positive technologies for individual and group flourishing. In A. L. Brooks, S. 
Brahman \& L. C. Jain (Eds.), Technologies of Inclusive Well-Being (pp. 221-244). Springer Berlin Heidelberg.

Argyle, M., \& Dean, J. (1965). Eye contact, distance, and affiliation. Sociometry, 28, 289304.

Biocca, F., Burgoon, J.K., Harms, C., Stoner, M. (2001). Criteria and scope conditions for a theory and measure of social presence. Paper presented at Presence Conference 2001, Philadelphia, PA

Biocca, F., Harms, C., Burgoon, J. (2001). Toward a more robust theory and measure of social presence: Review and suggested criteria. Presence, 12, 456-480. 2003.

Boyatzis, R. (1998). Transforming qualitative information: Thematic analysis and code development. Thousand Oaks, CA: Sage

Braun, V., \& Clarke, V. (2006). Using thematic analysis in psychology. Qualitative Research in Psychology, 3, 77-101

Brown, E., \& Cairns, P. (2004, April). A grounded investigation of immersion in games. Paper presented at ACM Conference on Human Factors in Computing Systems, CHI 2004, Vienna, Austria

Chiang, Y. T., Lin, S. S., Cheng, C. Y., \& Liu, E. Z. F. (2011). Exploring Online Game Players' Flow Experiences and Positive Affect. Turkish Online Journal of Educational Technology, 10 (1), 106-114 
Crabtree, B., \& Miller, W. (1999). A template approach to text analysis: Developing and using codebooks. In B. Crabtree \& W. Miller (Eds.), Doing qualitative research (pp. 163-177). Newbury Park, CA: Sage.

Csikszentmihalyi, M. (1975). Beyond boredom and anxiety: Experiencing flow in work and play. San Francisco: Jossey-Bass Publishers

de Kort, Y. A. W., IJsselsteijn, W. A., \& Poels, K. (2007, October). Digital Games as Social Presence Technology: Development of the Social Presence in Gaming Questionnaire (SPGQ). Paper presented at PRESENCE Conference 2007, Barcelona, Spain.

Eastin, M. S. (2006) Video game violence and the female game player: Self and opponent gender effects on presence and aggressive thoughts. Human Communication Research $31(3), 351-372$

Eastin, M. S. (2007). The influence of competitive and cooperative group game play on state hostility. Human Communication Research 33, 450-466. doi: 10.1111/j.14682958.2007.00307.x

Fereday, J., \& Muir-Cochrane, E. (2006). Demonstrating rigor using thematic analysis: A hybrid approach to inductive and deductive coding and theme development. International Journal of Qualitative Methods, 5 (1), 80-92

Gaggioli, A., Milani, L., Mazzoni, E., \& Riva, G. (2011). Networked flow: A framework for understanding the dynamics of creative collaboration in educational and training settings. The Open Education Journal, 4 (1), 41-49 
Gaggioli, A., Riva, G., Milani, L., \& Mazzoni, E. (2012). Networked flow: Towards an understanding of creative networks. Springer Science \& Business Media.

Gajadhar, B. J., de Kort, Y. A. W., \& Ijsselsteij, W. A. (2008, April). Influence of social setting on player experience of digital games. Paper presented at CHI 2008 Conference, Florence, Italy

Gajadhar, B. J., de Kort, Y. A. W., \& IJsselsteijn, W. A. (2009a). Rules of engagement: Influence of co-player presence on player involvement in digital games. International Journal of Gaming and Computer-Mediated Simulations 1 (3), 14-27. doi:10.4018/jgcms.2009070102

Gajadhar, B. J., de Kort, Y. A. W., \& IJsselsteijn, W. A. (2009b, June). See no rival, hear no rival: The role of social cues in digital game settings. Paper presented at the 13th CHI 2009 Conference, Leiden, Netherlands

Gee, J. P. (2003). What videogames have to teach us about learning and literacy. New York: Palgrave Macmillian

Goffman, E. (1956). The Presentation of Self in Everyday Life. New York: Anchor Books.

Hall, E. T. (1959). The Silent Language. New York: Doubleday. 
Jackson, S. A., \& Eklund, R. C. (2002). Assessing flow in physical activity: The Flow State Scale-2 and the Dispositional Flow Scale-2. Journal of Sport and Exercise Psychology 24, 133-150

Jackson, S. A., \& Marsh, H.W. (1996). Development and validation of a scale to measure optimal experience: The flow state scale. Journal of Sport and Exercise Psychology, $18,17-35$

Jackson, S. A., Martin, A. J., \& Eklund, R. C. (2008). Long and short measures of flow: The construct validity of the FSS-2, DFS-2 and new brief counterparts. Journal of Sport and Exercise Psychology, 30, 561-587

Juul, J. (2010). A Casual Revolution: Reinventing video games and their players. MIT Press

Kaye, L. K., \& Bryce, J. (2012). Putting the "fun factor" into gaming: The influence of social contexts on experiences of playing videogames. International Journal of Internet Science, 7 (1), 23-37

Kaye, L. K., \& Bryce, J. (2014). Go with the flow: The experience and affective outcomes of solo versus social gameplay. Journal of Gaming and Virtual Worlds, 6 (1), 49-60. doi: 10.1386/jgvw.6.1.49_1

Lim, S, \& Lee, J. R. (2009). When playing together feels different: Effects of task types and social contexts on physiological arousal in multiplayer online gaming contexts. CyberPsychology \& Behavior, 12 (1), 59-61. doi: 10.1089/cpb.2008.0054 
Lim, S., \& Reeves, B. (2010). Computer agents versus avatars: Responses to interactive game characters controlled by a computer or other player. International Journal of HumanComputer Studies, 68 (1-2), 57-68

Loftus, E. F., \& Hoffman, H. G. (1989). Misinformation and Memory: The Creation of New Memories. Journal of Experimental Psychology: General 118 (1):100-104

Mandryk, R., Inkpen, K. M., \& Calvert, T. W. (2006). Using psychophysiological techniques to measure user experience with entertainment technologies. Behaviour and Information Technology 25 (2), 141-158

Nakamura, J., \& Csikszentmihalyi, M. (2002). The concept of flow. In C. R. Snyder \& S. J. Lopez (Eds.), Handbook of positive psychology (pp. 89-105). Oxford: Oxford University Press

Prensky, M. (2001). Digital game-based learning. New York: McGraw-Hill

Ravaja, N., Saari, T., Turpeinen, M., Laarni, J., Salminen, M., \& Kivikangas, M. (2006). Spatial presence and emotions during video game playing: Does it matter with whom you play? Presence: Teleoperators and Virtual Environments 15 (4), 381-392

Rufi, S., Wlodarczyk, A., Páez, D., \& Javaloy, F. (in press). 'Flow and emotional experience in Spirituality: Differences in interactive and coactive collective rituals.' Journal of Humanistic Psychology. doi: 10.1177/0022167815571597 
Sato, I. (1988). Bosozoku: Flow in Japanese motorcycle gangs. In M. Csikszentmihalyi \& I. Csikszentmihalyi (Eds.), Optimal experience: Psychological studies of flow in consciousness (pp. 92-117). Cambridge: Cambridge University Press

Sawyer, K. (2008). Group genius: The creative power of collaboration. Basic Books.

Walker, C. J. (2010). 'Experiencing flow: Is doing it together better than doing it alone?' The Journal of Positive Psychology, 5 (10), 3-11. doi:10.1080/17439760903271116

Watson, D., Clark, L. A., \& Tellegen, A. (1988). Development and validation of brief measures of Positive and Negative Affect: The PANAS Scales. Journal of Personality and Social Psychology, 54 (6), 1063-1070 
Table 1: Descriptive analyses for flow and post-gameplay mood for solo and cooperative gaming experiences, and sub-analysis between online and offline

\section{Gaming Context}

\begin{tabular}{|c|c|c|c|c|c|c|c|c|}
\hline & \multicolumn{2}{|c|}{ Solo } & \multicolumn{2}{|c|}{ Cooperative } & \multicolumn{2}{|c|}{ Online } & \multicolumn{2}{|c|}{ Offline } \\
\hline & $\mathbf{M}$ & SD & $\mathbf{M}$ & SD & $\mathbf{M}$ & SD & $\mathbf{M}$ & SD \\
\hline Flow & $4.14 *$ & .52 & $3.90^{*}$ & .60 & 3.91 & .64 & 3.89 & .50 \\
\hline Positive Mood & 3.21 & .88 & 3.24 & 1.02 & 3.20 & 1.10 & 3.19 & .86 \\
\hline Negative Mood & 1.29 & .32 & 1.36 & .07 & 1.43 & .58 & 1.39 & .76 \\
\hline
\end{tabular}


Table 2: Correlations between group flow items with positive and negative post-gameplay $\operatorname{mood}$

$\begin{array}{lllll}2 & 3 & 4 & 5 & 6\end{array}$

1.Positive Mood .27

$.52 * *$

$.34 *$

$.30^{*}$

$.31^{*}$

2. Negative Mood

$-.16$

$-.12$

$-.16$

$-.20$

3. Task-relevant knowledge/skills

$.14 \quad .21 \quad .50 * *$

4. Team-work

$.29 *$

(Interdependence, coordination, cooperation)

5. Team-work

(Complementary participation)

6. Communication

$* * p<.001 \quad * p<.05$ 